with multiple abscesses in the brain substance which were diagnosed as tuberculous. The eye was not obtained.

The interesting point arises as to whether it would have been wise to remove the eye. Looking back on it I think it would, as there were no definite signs of tubercle elsewhere.

\title{
A CASE OF INTRA-OCULAR SARCOMA OF UNKNOWN ORIGIN CAUSING THE SYMPTOMS OF AN ACUTE HYALITIS
}

\author{
BY \\ T. HARRISON BUtLER \\ AND \\ Eric W. Assinder \\ Pathologist, Birmingham Eye Hospital
}

THIS case seems worthy of record, first, because there is some doubt as to whether the tumour arose from the sclera or from the choroid, and, secondly, because it gave rise to symptoms that suggested a septic hyalitis.

Ada C., aged 28 years, was admitted to the Birmingham Eye Hospital complaining of great pain in her eye.

History. Was confined three weeks ago. There was nothing abnormal during the confinement or the puerperium.

For the past eight months she has noted that the sight of the left eye was dull.

For the past few days the left eye has been inflamed and painful.

Present condition. The patient is obviously ill, her breath is foul, and her temperature raised.

The left lids are oedematous. The eye is intensely injected. The cornea is steamy, and the tension is plus 3 .

On the temporal side, deep in the eye, there is seen a pinky. yellowish mass. The retina is detached over it.

Transillumination gives an opaque shadow on the temporal side.

It was considered that there was a septic inflammation of the eye, and that the mass was inflammatory. It was supposed that the septic condition was connected with the confinement. The general condition of the patient, who was quite obviously very ill, lent support to this view; although the fact that the eye had been abnormal for some months was against this diagnosis. 


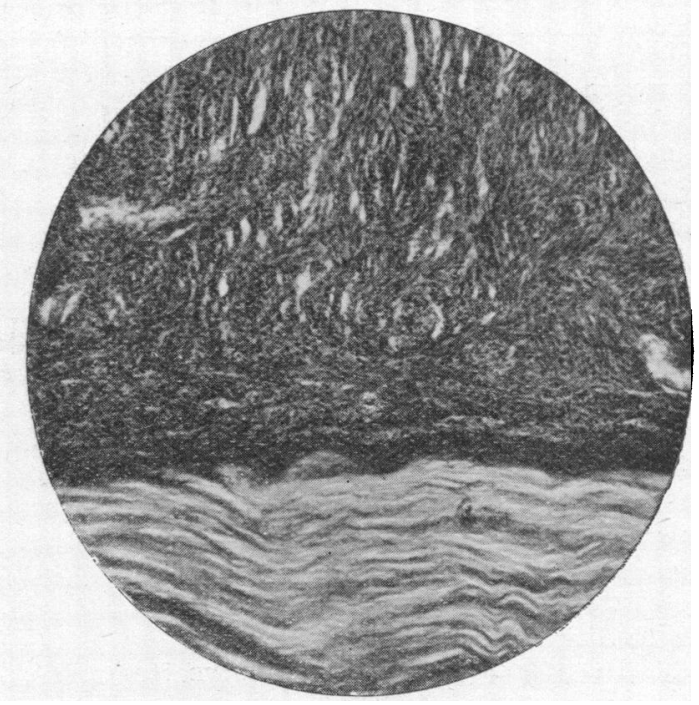

Section of spindle-celled sarcoma

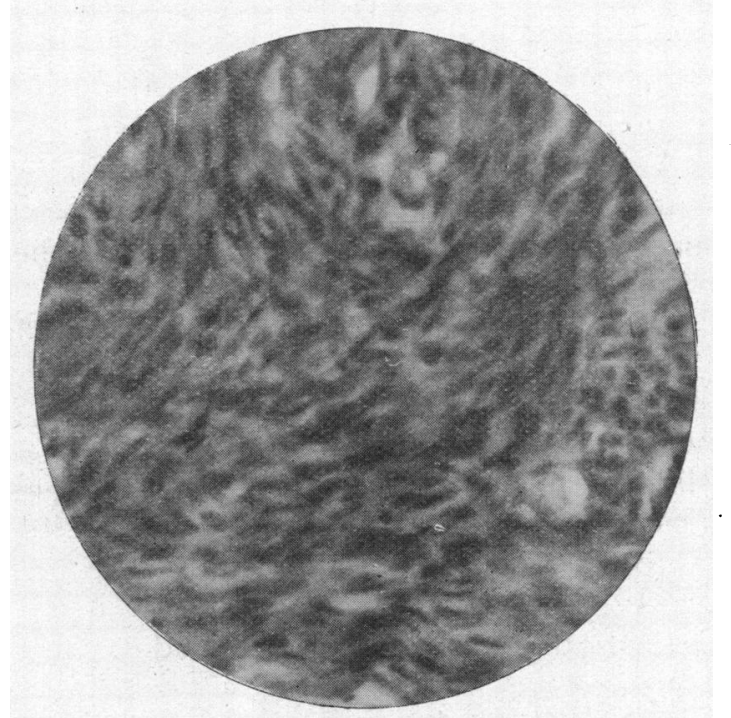

Section of spindle-ceiled sarcoma. Higher Magnification. 


\section{Pathological examination of the eye}

When the eye was bisected a spherical white tumour the size of a small.cherry was seen attached to the sclera on the temporal side. It had the appearance of growing from the sclera and its macroscopic appearance was similar to that of scleral tissue. The attachment to the sclera was stalk-like. At its periphery it was again firmly adherent to the tunics of the eye and appeared here to be growing from the sclera.

The tumour on section showed a spindle-celled, non-pigmented sarcoma.

The fact that the tumour is non-pigmented is in favour of its scleral origin: most choroidal tumours are pigmented, but not all. On the whole, I (E.W.A.) am in favour of the choroidal origin, and I consider that it has arisen from non-pigmented cells in the choroid, and that its stalk-like attachment to the sclerotic is an invasion of the sclera by tumour cells.

\section{ANNUAL CONGRESS OF THE OPHTHALMOLOGICAL SOCIETY OF THE UNITED KINGDOM}

THE Twelfth Annual Congress of the Society was held at Glasgow on Thursday, Friday and Saturday, May 1-3, 1924.

This is the first extra-Metropolitan meeting of the Congress since it became an annual event. The meetings were well attended, and the admirable local arrangements did much to render the Congress an unqualified success.

The President, Dr. A. Maitland Ramsay, was in the chair, and the meetings were held in the Department of Zoology of the Glasgow University, and on Friday evening in the Anatomical Theatre.

The proceedings opened by a cordial address of welcome to the Congress by Sir Donald MacAlister, Bart., Principal of the University. This was immediately followed by the discussion, which was on "The Physiology and Pathology of the Pupil Reactions."

Sir JOHN PARSONS opened with a very comprehensive survey of our present knowledge of the subject from the physiological standpoint. He described the musculature and nerve supply of the pupil, the proof of the presence of dilatator fibres, the light, sensory and associated reflexes. The various experimental and pathological proofs of the course of the light reflex and the very close association of the visual and pupil responses to light were also reviewed.

$\mathrm{He}$ discussed the retained reaction of the pupil to light in cases of optic atrophy with blindness. He next considered the state of 